\title{
Composição química de aguardente de cana obtida por diferentes métodos de destilação
}

\section{Chemical composition of sugar cane spirit produced from different distillation methods}

\author{
Arthur Paron de Silva ${ }^{1}$, Giovanni Casagrande Silvello', Aline Marques Bortolettoㄹ, \\ André Ricardo Alcarde ${ }^{1 *}$ (i) \\ 1Universidade de São Paulo (USP), Escola Superior de Agricultura "Luiz de Queiroz" (ESALQ), Piracicaba/SP - Brasil \\ ${ }^{*}$ Corresponding Author: André Ricardo Alcarde, Universidade de São Paulo (USP), Escola Superior de \\ Agricultura "Luiz de Queiroz" (ESALQ), Av. Pádua Dias, 11, CP 9, CEP: 13418-900, Piracicaba/SP, Brasil, \\ e-mail: andre.alcarde@usp.br
}

Cite as: Silva, A. P., Silvello, G. C., Bortoletto, A. M., \& Alcarde, A. R. (2020). Chemical composition of sugar cane spirit produced from different distillation methods. Brazilian Journal of Food Technology, 23, e2018308.

https://doi.org/10.1590/1981-6723.30818

\begin{abstract}
Resumo
O presente estudo teve por objetivo determinar a influência de métodos de destilação (simples, dupla e redestilação) na composição química de aguardentes de cana, mediante análises de componentes voláteis (aldeídos, ésteres, metanol, álcoois superiores, ácido acético e furfural) e contaminantes (álcoois n-butílico e sec-butílico, cobre e carbamato de etila). A aguardente monodestilada e os destilados alcoólicos das aguardentes bidestilada e redestiladas apresentaram composição química de compostos voláteis e de contaminantes dentro das especificações da legislação brasileira. A aguardente monodestilada apresentou maiores concentrações de ácido acético, aldeído acético, acetato de etila, álcool propílico, álcoois superiores, furfural e coeficiente de congêneres. A aguardente monodestilada também apresentou concentrações mais elevadas dos contaminantes metanol, sec-butanol, cobre e carbamato de etila. Em relação à monodestilação, as metodologias de bidestilação e de redestilação proporcionaram redução da concentração de congêneres voláteis das aguardentes (ácido acético, aldeído acético, acetato de etila, álcool propílico e furfural) e de compostos considerados contaminantes (metanol, sec-butanol, cobre e carbamato de etila).
\end{abstract}

Palavras-chave: Cachaça; Alambique; Destilação simples; Redestilação; Destilação dupla; Congêneres.

\begin{abstract}
This study aimed to determine the influence of distillation methods (single, double and redistillation) on the chemical composition of sugar cane spirits. Analysis of volatile compounds (aldehydes, esters, methanol, higher alcohols, acetic acid and furfural) and contaminants (n-butyl and sec-butyl alcohols, copper and ethyl carbamate) were carried out. All the distilled spirits presented chemical composition of volatiles and contaminants within Brazilian legal specifications. The single distilled sugar cane spirit presented higher concentrations of acetic acid, acetaldehyde, ethyl acetate, propyl alcohol, higher alcohols, furfural, and coefficient of congeners. The single distilled sugar cane spirit also presented higher concentrations of contaminants (methanol, sec-butyl alcohol,
\end{abstract}


copper and ethyl carbamate). The methodologies of double distillation and redistillation provided a reduction in the concentration of volatile congeners (acetic acid, acetaldehyde, ethyl acetate, propyl alcohol, and furfural) and contaminants (methanol, sec-butyl alcohol, copper and ethyl carbamate) of the sugar cane spirits.

Keywords: Cachaça; Pot still; Single distillation; Redistillation; Double distillation; Congeners.

\section{Introdução}

Aguardente de cana é a bebida com graduação alcoólica de 38 a 54\% (v/v), obtida do destilado alcoólico simples de cana-de-açúcar ou pela destilação do mosto fermentado do caldo de cana-de-açúcar. Destilado alcoólico simples de cana-de-açúcar é o produto obtido pelo processo de destilação simples ou por destilo-retificação parcial seletiva do mosto fermentado do caldo de cana-de-açúcar, com graduação alcoólica de 54 a $70 \%$ (v/v).

Aguardente de cana pode ser produzida mediante destilação em colunas contínuas ou em alambiques intermitentes. Na destilação em alambiques, existem variações no processo, tais como a monodestilação, a bidestilação e a redestilação. O processo tradicional para produção de aguardente de cana-de-açúcar é a monodestilação. No início da destilação do vinho, realiza-se a separação da fração "cabeça", correspondente a 1,5\% do volume útil da caldeira. Então começa a se recolher a fração "coração", a qual será utilizada para produção da aguardente, sendo esta recolhida até que o teor alcoólico do destilado na saída do condensador esteja em torno de $38 \%$ a $40 \%$ (v/v), sendo a concentração alcoólica média entre $44 \%$ e $48 \%$ nesta fração do destilado. Em seguida, começa a fração "cauda", também conhecida como "água fraca", e esta é destilada até que o destilado na saída do condensador apresente-se isento de etanol.

A dupla destilação, também conhecida por bidestilação, é o processo pelo qual se realizam duas destilações sucessivas. Primeiramente, o vinho passa por uma destilação em que se objetiva separar todo o álcool nele contido, numa fração única denominada flegma, que, em média, possui $28 \%$ (v/v) de álcool. Então, em um segundo processo, a flegma é destilado e só então se procede à separação das frações: "cabeça" (1\% do volume útil da caldeira), "coração" (destilado recuperado com até aproximadamente $60 \%$ de etanol na saída do condensador) e "cauda" (destilado de $60 \%$ até o esgotamento do etanol na saída do condensador). Esse processo visa à produção de uma bebida com menor teor de congêneres, voltada para o envelhecimento em barris de madeira.

A redestilação é um processo semelhante à bidestilação, porém, em vez da flegma, utiliza para a segunda destilação um destilado alcoólico industrial, usualmente diluído com água potável para aproximadamente $30 \%$ (v/v) de etanol. Portanto, neste método, não é realizada a primeira destilação.

A Instrução Normativa n. ${ }^{\circ} 13$ (IN 13), de 29/06/2005, do Ministério da Agricultura, Pecuária e Abastecimento (MAPA) do Brasil, estabelece o Padrão de Identidade e Qualidade (PIQ) para aguardente de cana-de-açúcar (Brasil, 2005a). Nesta normativa, constam os limites para componentes voláteis "não álcool" e contaminantes orgânicos e inorgânicos que podem estar presentes na bebida, visando padronizar essas bebidas e proteger o consumidor.

Durante o processo de fermentação alcoólica do mosto preparado a partir do caldo de cana, as leveduras transformam os açúcares presentes no mosto em etanol e gás carbônico como produtos principais. Porém, vários outros compostos são formados em menores quantidades, tais como ácidos orgânicos, metanol, ésteres, aldeídos e álcoois superiores. Tais compostos contribuem para a formação do aroma e do sabor de bebidas destiladas (Moreira et al., 2012).

A fração volátil das aguardentes de cana está diretamente relacionada com a qualidade e a aceitação sensorial da bebida. Todas as etapas do processo de produção da aguardente influenciam a composição qualitativa e quantitativa da fração volátil da bebida. Apesar de serem os principais componentes das aguardentes de cana, o etanol e a água pouco influenciam o sabor e o aroma dessas bebidas, pois são os 
compostos secundários que determinam a percepção sensorial da aguardente. Os álcoois, ésteres, aldeídos e ácidos são os grupos de compostos que mais contribuem neste sentido.

Este trabalho teve por objetivo determinar a influência de métodos de destilação (simples, dupla e redestilação) na composição química de aguardentes de cana, mediante análises de componentes voláteis (aldeídos, ésteres, metanol, álcoois superiores, ácido acético e furfural) e contaminantes (álcoois n-butílico e sec-butílico, cobre e carbamato de etila). Na redestilação, foram testadas diluições do destilado alcoólico para resultar em flegmas com 30\%, 40\% e 48\% de etanol (v/v) para a destilação.

\section{Material e métodos}

O experimento foi conduzido nas instalações do Laboratório de Tecnologia e Qualidade de Cachaça do Departamento de Agroindústria, Alimentos e Nutrição da ESALQ/USP. Todas as aguardentes do projeto foram produzidas em triplicata.

\subsection{Obtenção da aguardente monodestilada}

Colmos de cana-de-açúcar da variedade SP 81-3250, cultivada na ESALQ, foram esmagados em moenda e o caldo extraído foi decantado para a retirada das impurezas sólidas. A concentração de sólidos solúveis do caldo decantado foi ajustada para $18^{\circ}$ Brix, mediante diluição com água potável, em tanques de diluição de caldo. O caldo diluído foi encaminhado a dornas de fermentação de $1.500 \mathrm{~L}$, nas quais recebeu a inoculação de 1,5 kg fermento selecionado, cepa CA-11 (LNF, Bento Gonçalves-RS), previamente reativado conforme as recomendações do fabricante. A fermentação transcorreu por $36 \mathrm{~h}$ a $32^{\circ} \mathrm{C}$.

A aguardente monodestilada foi obtida a partir da destilação do mosto de caldo de cana fermentado (vinho de cana) em alambique equipado com coluna concentração de dois pratos e deflegmador (Santa Efigênia, Itaverava-MG), de $1.000 \mathrm{~L}$ de volume útil, aquecido a vapor proveniente de caldeira automática a gás modelo MGV 200 (Maritec, Oriente-SP), com capacidade de produção de $200 \mathrm{~kg}$ de vapor por hora e operando a $6 \mathrm{kgf} / \mathrm{cm}^{2}$. Na destilação, procedeu-se à separação das frações: "cabeça" (15 L iniciais de destilado, o que correspondeu a $1,5 \%$ do volume de vinho em destilação), "coração" (destilado recuperado após a fração "cabeça" e até atingir o grau alcoólico de $38 \%$ (v/v) no destilado na saída do resfriador) e "cauda" (destilado recuperado após a fração "coração" e até esgotamento do etanol na saída do condensador). A fração "coração" representou a aguardente monodestilada.

\subsection{Obtenção da aguardente bidestilada}

O vinho de cana, obtido conforme descrito para o processo de monodestilação, foi submetido à primeira destilação, visando o esgotamento do etanol na caldeira do alambique, sem efetuar separação de frações, originando a flegma. Para se obter volume suficiente de flegma para a segunda destilação foram necessárias três primeiras destilações, sendo as flegmas parciais armazenados em tanques de aço inoxidável. Na segunda destilação, a da flegma, procedeu-se à separação das frações: "cabeça" (10 L iniciais de destilado, o que corresponde a $1 \%$ do volume de flegma em destilação), "coração" (destilado recuperado após a fração "cabeça" e até atingir o grau alcoólico de $60 \%$ (v/v) no destilado na saída do resfriador) e "cauda" (destilado recuperado após a fração "coração" e até esgotamento do etanol na saída do condensador). A fração "coração" representou a aguardente bidestilada.

\subsection{Obtenção da aguardente redestilada}

A aguardente redestilada foi obtida a partir da destilação do destilado alcoólico obtido no processo de produção da aguardente monodestilada ( $48 \%$ de etanol, $\mathrm{v} / \mathrm{v})$, integral e também convenientemente diluído com água potável para resultar em teores alcoólicos de $40 \%$ e $30 \%$ (v/v) na flegma. Durante a destilação 
procedeu-se à separação das frações: "cabeça" (10 L iniciais de destilado, o que corresponde a $1 \%$ do volume de flegma em destilação), "coração" (destilado recuperado após a fração "cabeça" e até atingir o grau alcoólico de $60 \%$ (v/v) no destilado na saída do resfriador) e "cauda" (destilado recuperado após a fração "coração" e até esgotamento do etanol na saída do condensador). As frações "coração" representaram as aguardentes redestiladas.

\subsection{Análises químicas}

As aguardentes foram analisadas quanto à concentração de etanol mediante análise de massa específica em densímetro digital marca Anton Paar, modelo DMA 4500, após destilação prévia da amostra em destilador de laboratório (Brasil, 2005b).

As amostras foram submetidas às análises de concentração de aldeído acético, acetato de etila, metanol, álcoois superiores (propanol, iso-butanol, iso-amílico), n-butanol, sec-butanol e ácido acético, mediante técnica de cromatografia gasosa (Bortoletto \& Alcarde, 2013) em cromatógrafo Shimadzu modelo GC-2010 PLUS, equipado com coluna cromatográfica capilar STABILWAX-DA $(30 \mathrm{~m} \times 0,25 \mathrm{~mm} \times 0,25 \mu \mathrm{m})$, com detector de ionização de chama (FID). $\mathrm{O}$ gás de arraste foi $\mathrm{N}_{2}$, com fluxo de $1,2 \mathrm{~mL} / \mathrm{min}$. A temperatura do injetor foi $220^{\circ} \mathrm{C}$ e a temperatura da coluna foi programada para $35^{\circ} \mathrm{C}$ por $5 \mathrm{~min}$, aumento até $220^{\circ} \mathrm{C}$ a uma proporção de $4{ }^{\circ} \mathrm{C} / \mathrm{min}$, com retenção de 10 min a $220^{\circ} \mathrm{C}$. A temperatura do detector foi $220^{\circ} \mathrm{C}$. A injeção foi automática, de $1,0 \mu \mathrm{L}$ de amostra.

A determinação da concentração de carbamato de etila foi realizada utilizando um cromatógrafo Shimadzu GC-2010, com detector de massas Shimadzu GCMS-QP-2010 PLUS, operando em modo SIM ( $\mathrm{m} / \mathrm{z}=62)$, equipado com coluna cromatográfica capilar de fase polar (polietilenoglicol esterificada), HP-FFAP $(49 \mathrm{~m} \times 0,20 \mathrm{~mm} \times 0,33 \mu \mathrm{m})$. As temperaturas do injetor e da interface do detector foram $230{ }^{\circ} \mathrm{C}$ e $240{ }^{\circ} \mathrm{C}$, respectivamente. Empregou-se a seguinte programação de temperatura para o forno: início com $90{ }^{\circ} \mathrm{C}$ (2 min), elevação para $150{ }^{\circ} \mathrm{C}$ a uma taxa de $10{ }^{\circ} \mathrm{C} / \mathrm{min}$, seguida de aquecimento para $220^{\circ} \mathrm{C}$ a uma proporção de $40^{\circ} \mathrm{C} / \mathrm{min}$, na qual permaneceu por $2 \mathrm{~min}$. O volume injetado foi de $2,0 \mu \mathrm{L}$ no modo "splitless" automático. O gás de arraste foi hélio com fluxo de 1,5 mL/min (Alcarde et al., 2012a).

\subsubsection{Curvas analíticas cromatográficas}

A quantificação dos compostos foi realizada com base em curvas analíticas externas de seis pontos de concentração padrão. $\mathrm{O}$ intervalo de concentração e os coeficientes de correlação $\left(\mathrm{a}, \mathrm{b}, \mathrm{r}^{2}\right)$, assim como os índices de retenção, limite de detecção (LD) e o limite de quantificação (LQ) dos compostos voláteis (Tabela 1), foram calculados com base no ruído da linha de base dos cromatogramas, seguindo metodologia de Lanças (2009).

Tabela 1. Índices de retenção (IR), limite de detecção (LD), limite de quantificação (LQ) dos compostos voláteis, intervalo de concentração (IC) e coeficientes de correlação (a, b, $\left.\mathrm{r}^{2}\right)$ das curvas analíticas em soluções alcoólicas (40\% de álcool v/v) para quantificação dos compostos.

\begin{tabular}{cccccccc}
\hline Compostos Voláteis & $\begin{array}{c}\text { IR } \\
(\mathbf{m i n})\end{array}$ & $\begin{array}{c}\text { LD } \\
(\mathbf{m g} / \mathbf{1 0 0} \mathbf{~ m L} \\
\text { álcool anidro) }\end{array}$ & $\begin{array}{c}\text { LQ } \\
(\mathbf{m g} / \mathbf{1 0 0} \mathbf{~ m L} \\
\text { álcool anidro) }\end{array}$ & $\begin{array}{c}\text { IC } \\
(\mathbf{m g} / \mathbf{1 0 0} \mathbf{~ m L} \\
\text { álcool anidro) }\end{array}$ & $\mathbf{a}$ & $\mathbf{b}$ & $\mathbf{r}^{\mathbf{2}}$ \\
\hline Aldeído acético & 0,29 & 0,070 & 0,220 & $7,5-37,5$ & 5,5900 & $-1,0200$ & 0,9957 \\
\hline Acetato de etila & 1,41 & 0,057 & 0,171 & $12,5-62,5$ & 2,8792 & 0,9075 & 0,9996 \\
\hline Álcool n-propílico & 4,43 & 0,038 & 0,114 & $37,5-187,5$ & 2,0471 & $-0,2444$ & 0,9999 \\
\hline Álcool isobutílico & 5,22 & 0,014 & 0,042 & $12,5-62,5$ & 1,7260 & $-0,1724$ & 0,9998 \\
\hline Álcool iso-amílico & 6,72 & 0,016 & 0,048 & $50-250$ & 1,6748 & 9,1053 & 0,9999 \\
\hline Ácido acético & 9,15 & 0,530 & 1,590 & $37,5-187,5$ & 5,4259 & 4,1160 & 0,9997 \\
\hline Álcool metílico & 1,62 & 0,092 & 0,276 & $5-25$ & 4,1394 & $-0,1620$ & 0,9997 \\
\hline Álcool sec-butílico & 4,02 & 0,049 & 0,180 & $2,5-12,5$ & 1,9168 & $-5,1082$ & 0,9998 \\
\hline Álcool n-butílico & 5,99 & 0,072 & 0,216 & $0,75-3,75$ & 1,1168 & $-1,8590$ & 0,9997 \\
\hline Carbamato de etila & 10,15 & $1,80^{1}$ & $5,55^{1}$ & $50-500^{1}$ & 174,487 & $-38,857$ & 0,9920 \\
\hline
\end{tabular}

${ }^{1}(\mu \mathrm{g} / \mathrm{L})$. 


\subsection{Análise estatística}

Os resultados foram analisados estatisticamente por análise de variância (ANOVA) e Testes de Tukey, dentro de um delineamento experimental em três blocos casualizados, referentes às aguardentes monodestilada, bidestilada e redestilada, com três repetições por bloco (Pimentel-Gomes \& Garcia, 2002), mediante uso do programa estatístico SAS (SAS - EUA).

\section{Resultados e discussão}

A aguardente monodestilada e os destilados alcoólicos das aguardentes bidestilada e redestiladas apresentaram composição química de compostos voláteis e de contaminantes dentro das especificações da IN 13 (Tabela 2).

Tabela 2. Composição químicas da aguardente monodestilada e dos destilados alcoólicos simples (DAS) que originaram as aguardentes bidestilada e redestiladas.

\begin{tabular}{|c|c|c|c|c|c|c|}
\hline Itens analisados / Amostras & $\begin{array}{c}\text { Aguardente } \\
\text { Monodestilada }\end{array}$ & $\begin{array}{c}\text { DAS } \\
\text { Bidestilada } \\
\end{array}$ & $\begin{array}{c}\text { DAS } \\
\text { (flegma } 30 \%) \\
\end{array}$ & $\begin{array}{c}\text { DAS } \\
\text { (flegma } 40 \%) \\
\end{array}$ & $\begin{array}{c}\text { DAS } \\
\text { (flegma } 50 \%) \\
\end{array}$ & IN 13 \\
\hline $\begin{array}{c}\text { Grau alcoólico real } \\
\left(\% \mathrm{v} / \mathrm{v} \text { a } 20^{\circ} \mathrm{C}\right)\end{array}$ & $47,86+0,13^{\mathrm{c}}$ & $65,26+1,77^{b}$ & $65,04+2,22^{b}$ & $67,41+1,10^{\mathrm{a}}$ & $69,81+1,11^{\mathrm{a}}$ & $\begin{array}{l}38-54^{1} \\
54-70^{2}\end{array}$ \\
\hline $\begin{array}{c}\text { Acidez volátil em ácido } \\
\text { acético }^{3}\end{array}$ & $42,27+2,13^{a}$ & $11,54+0,81^{b}$ & $6,75+0,18^{c}$ & $6,81+0,24^{c}$ & $6,38+0,34^{c}$ & $<150$ \\
\hline Aldeídos em aldeído acético ${ }^{3}$ & $18,16+2,02^{\mathrm{a}}$ & $14,90+1,47^{b}$ & $10,75+0,88^{c}$ & $9,53+2,00^{\mathrm{c}}$ & $11,19+1,30^{c}$ & $<30$ \\
\hline Ésteres em acetato de etila ${ }^{3}$ & $17,83+0,81^{\mathrm{a}}$ & $14,39+2,88^{\mathrm{b}}$ & $15,44+2,61^{\mathrm{b}}$ & $13,24+2,32^{\mathrm{b}}$ & $14,57+2,95^{\mathrm{b}}$ & $<200$ \\
\hline Álcool metílico ${ }^{3}$ & $8,26+0,16^{\mathrm{a}}$ & $3,17+0,12^{b}$ & $0,47+0,04^{\mathrm{c}}$ & $0,39+0,06^{\mathrm{c}}$ & $0,55+0,09^{c}$ & $<20$ \\
\hline Álcool sec-butílico ${ }^{3}$ & $3,14+0,06^{\mathrm{a}}$ & $0,93+0,02^{b}$ & $0,97+0,03^{b}$ & $1,01+0,01^{\mathrm{b}}$ & $0,99+0,01^{\mathrm{b}}$ & $<10$ \\
\hline Álcool propílico ${ }^{3}$ & $89,15+1,21^{\mathrm{a}}$ & $74,21+0,99^{b}$ & $59,55+1,83^{\mathrm{c}}$ & $60,27+0,79^{c}$ & $58,96+0,66^{\mathrm{c}}$ & \\
\hline Álcool iso-butílico ${ }^{3}$ & $57,91+1,44^{\mathrm{a}}$ & $46,07+0,66^{\mathrm{a}}$ & $51,01+1,81^{\mathrm{a}}$ & $52,17+0,91^{\mathrm{a}}$ & $51,50+0,70^{\mathrm{a}}$ & \\
\hline Álcool n-butílico ${ }^{3}$ & $1,66+0,05^{\mathrm{a}}$ & $1,51+0,04^{\mathrm{a}}$ & $0,76+0,03^{\mathrm{b}}$ & $0,76+0,01^{\mathrm{b}}$ & $0,74+0,02^{\mathrm{b}}$ & $<3$ \\
\hline Álcool iso-amílico ${ }^{3}$ & $191,58+7,01^{\mathrm{a}}$ & $196,66+6,95^{\mathrm{a}}$ & $205,28+9,17^{\mathrm{a}}$ & $209,13+6,70^{\mathrm{a}}$ & $198,02+5,39^{a}$ & \\
\hline Álcoois superiores ${ }^{3}$ & $338,64+9,67^{\mathrm{a}}$ & $316,94+9,15^{b}$ & $315,84+12,75^{b}$ & $321,57+8,35^{\mathrm{b}}$ & $308,48+6,71^{\mathrm{b}}$ & $<360$ \\
\hline Furfural $^{3}$ & $0,12+0,02^{\mathrm{a}}$ & $0,02+0,00^{\mathrm{b}}$ & $<\mathrm{LD}$ & $<\mathrm{LD}$ & $<\mathrm{LD}$ & $<5$ \\
\hline Coeficiente de congêneres ${ }^{3}$ & $417,02+9,33^{a}$ & $357,79+8,37^{b}$ & $348,78+14,07^{\mathrm{b}}$ & $351,15+7,25^{\mathrm{b}}$ & $340,62+5,27^{b}$ & $200-650$ \\
\hline Cobre $^{4}$ & $1,98+0,06^{\mathrm{a}}$ & $0,62+0,03^{\mathrm{b}}$ & $0,42+0,02^{\mathrm{c}}$ & $0,37+0,02^{\mathrm{c}}$ & $0,39+0,02^{\mathrm{c}}$ & $<5$ \\
\hline Carbamato de etila ${ }^{5}$ & $70,35+5,18^{a}$ & $6,52+0,35^{b}$ & $<\mathrm{LD}$ & $<\mathrm{LD}$ & $<\mathrm{LD}$ & $<210$ \\
\hline
\end{tabular}

${ }^{1}$ Limites para a aguardente monodestilada; ${ }^{2}$ Limites para os destilados alcoólicos simples; ${ }^{3}(\mathrm{mg} / 100 \mathrm{~mL}$ álcool anidro $) ;{ }^{4}(\mathrm{mg} / \mathrm{L}) ;{ }^{5}(\mu \mathrm{g} / \mathrm{L}) ;$ LD = Limite de Detecção. Médias com letras iguais na linha não diferem entre si.

Por utilizar uma mistura hidroalcoólica com menor teor de etanol para a destilação, a aguardente monodestilada apresentou teor alcoólico menor que as aguardentes bidestilada e redestiladas (Tabela 2). Por outro lado, a aguardente monodestilada apresentou maiores concentrações de ácido acético, aldeído acético, acetato de etila, álcool propílico, álcoois superiores, furfural e coeficiente de congêneres. Com relação às aguardentes bidestilada e redestiladas, a aguardente monodestilada também apresentou concentrações mais elevadas dos contaminantes metanol, sec-butanol, cobre e carbamato de etila.

Por terem sido produzidos a partir de misturas hidroalcoólicas com teores mais elevados de etanol (30\% a $48 \% \mathrm{v} / \mathrm{v}$ ), os destilados obtidos na bidestilação e nas redestilações apresentaram concentração alcoólica mais elevada que a aguardente monodestilada (Tabela 2). Com relação aos destilados alcoólicos produzidos pela redestilação, o destilado alcoólico produzido pela bidestilação apresentou maiores concentrações de ácido acético, aldeído acético e álcool propílico, e também dos contaminantes metanol, n-butanol e cobre.

A água e o etanol são os principais componentes das aguardentes de cana, porém pouco influenciam o aroma e o sabor da bebida. Assim, a fração volátil da aguardente de cana está diretamente relacionada com os compostos secundários da bebida, responsáveis pela qualidade e pela aceitação sensorial. Como são compostos formados durante o processo de produção da aguardente, é necessária a adoção das Boas Práticas 
de Fabricação (BPF), para modular a formação destes compostos que compõem qualitativa e quantitativamente a fração volátil da bebida.

O etanol, principal álcool formado pela fermentação alcoólica, tem um limiar de percepção muito alto (100 ppm) e aroma pouco marcante. Assim, é o álcool que potencialmente tem menos representatividade na formação do aroma da bebida (Nóbrega, 2003). Além do etanol, as aguardentes de cana contêm outros álcoois, como o metanol, composto neurotóxico que afeta principalmente a retina e está associado ao consumo de bebidas adulteradas (Paine \& Davan, 2001), considerado, portanto, contaminante de bebidas destiladas. Ele é formado pela via de desmetoxilação da pectina encontrada nas fibras da cana, por ação da enzima pectinametilesterase (Mota et al., 2010). Por isso, é de suma importância a limpeza do caldo para fermentação, já que resíduos de bagacilho presentes no caldo, sob condições ácidas, possibilitam sua formação. O metanol é indesejável devido à sua toxicidade, causando, por exemplo, dor de cabeça, vertigens e vômitos. Se ingerido em grande quantidade ou por longo período, mesmo em pequenas doses, pode levar à cegueira (Paine \& Davan, 2001) e até à morte, por provocar acidose e disfunção celular (Piva et al., 1999).

O comumente conhecido "óleo fúsel" corresponde aos álcoois superiores, com três a cinco átomos de carbono, e são os componentes mais abundantes entre os compostos secundários da aguardente. O principal álcool superior é o álcool isoamílico (3-metil-1-butanol), seguido pelo n-propanol (1-propanol) e o isobutanol (2-metilpropan-1-ol). O n-butanol (1-butanol) e o sec-butanol (2-butanol) são contaminantes da aguardente, cujos teores máximos na bebida são controlados pela legislação. A formação dos álcoois superiores está associada às condições de fermentação e à cepa de levedura utilizada. Temperaturas de fermentação acima de $32{ }^{\circ} \mathrm{C}, \mathrm{pH}$ abaixo de 4,0 e a presença de oxigênio estimulam a produção de álcoois superiores pelas leveduras (Vilela et al., 2007). A degradação parcial de aminoácidos tem função reguladora do potencial redox das células de levedura, por meio da recuperação do NADH a partir do NAD+, que é reaproveitado na via glicolítica (Quain \& Duffield, 1985; Kruger, 1998), e leva à formação de álcoois superiores. Isoeucina e valina são aminoácidos precursores de álcool isoamílico e isobutanol, respectivamente. Treonina é precursor de n-propanol e n-butanol. As aguardentes produzidas por destilação em alambique normalmente apresentam maior concentração de álcoois superiores do que as aguardentes produzidas por destilação em colunas, nas quais os vapores alcoólicos normalmente atingem concentrações de etanol superiores a $60 \%$, permitindo assim a separação parcial dos álcoois superiores que, nestas concentrações de etanol, tendem a se acumular na fase líquida da matriz líquido-vapor em destilação dentro da coluna, da qual se separa o "óleo fúsel" (Whitby, 1992).

Os álcoois superiores possuem grande influência na formação dos sabores e aromas característicos das aguardentes. O álcool isoamílico está associado aos aromas de "malte", "uísque", "vínico", "banana" e "doce". O n-propanol tem odor "pungente". O isobutanol é associado a sabor "amargo". Murray (2014) apontou para a diferença na concentração de uísques destilados segundo diferentes metodologias: malt whiskey bidestilado em alambique apresentou concentração de álcoois superiores acima de $300 \mathrm{mg} / 100 \mathrm{~mL}$ de álcool anidro (a.a.), ao passo que grain whiskeys, destilados em coluna, apresentaram concentração máxima de $250 \mathrm{mg} / 100 \mathrm{~mL}$ a.a.

Características de odor dos compostos voláteis dependem de suas concentrações, de forma que quantidades muito elevadas podem modificar características de odor consideradas agradáveis para extremamente desagradáveis. Assim, destilados com quantidades excessivas de álcoois superiores normalmente apresentam aspecto sensorial desagradável. Em concentrações ao redor de $300 \mathrm{mg} / 100 \mathrm{~mL}$ a.a. e balanceadas entre eles, os álcoois superiores contribuem positivamente para a qualidade sensorial de aguardentes (Moreira et al., 2012). A aguardente monodestilada apresentou maior concentração de álcoois superiores, em relação aos demais tratamentos, com teor médio acima de $300 \mathrm{mg} / 100 \mathrm{~mL}$ a.a. Os álcoois superiores são importantes também pelas suas características como solventes, atuando sobre outras substancias aromáticas e alterando seus coeficientes de atividade e limiares de odor (Amerine \& Ough, 1976). 
Os ésteres têm grande influência no sabor e aroma de bebidas destiladas por apresentarem características de aroma quase sempre agradáveis (Wilson, 2008) e limiares de odor relativamente baixos. São formados intracelularmente e podem variar em função das diferentes respostas metabólicas das diferentes espécies e linhagens de leveduras. O principal éster presente em aguardentes é o acetato de etila, seguido pelo lactato de etila, representando cerca de $95 \%$ da quantidade total de ésteres da bebida. O acetato de etila é associado a odor "frutal", que se torna desagradável em altas concentrações. O lactato de etila também possui odor "frutado". A destilação em alambique normalmente contribui para uma maior concentração de ésteres em comparação às aguardentes produzidas por destilação em colunas contínuas, devido ao fato de as reações de esterificação serem catalisadas pelo cobre no ambiente aquecido da destilação. Por este motivo, as aguardentes obtidas pela destilação em alambique apresentam características frutadas mais intensas, originadas principalmente dos ésteres de cadeia curta (Nóbrega, 2003). A comparação entre concentrações de ésteres totais e acetato de etila em uísques destilados segundo diferentes metodologias foi realizada por Murray (2014), que apontou para concentrações de $40 \mathrm{mg} / 100 \mathrm{~mL}$ a.a. em uísque produzido a partir da metodologia de bidestilação e valores próximos de $20 \mathrm{mg} / 100 \mathrm{~mL}$ a.a. para destilação em coluna. De forma semelhante, dentre as aguardentes analisadas, a monodestilada apresentou maior média de concentração de acetato de etila $(18 \mathrm{mg} / 100 \mathrm{~mL}$ a.a.), sendo que, nos demais tratamentos, essas concentrações foram inferiores a $16 \mathrm{mg} / 100 \mathrm{~mL}$ a.a. (Tabela 2).

O ácido orgânico mais encontrado em aguardentes de cana é o ácido acético, representando de 90 a 93\% do conteúdo total de ácidos orgânicos da bebida. É primordial seu controle na qualidade das aguardentes de cana, pois quanto menor a acidez da bebida, melhor sua aceitação sensorial. São duas as suas origens: a principal é a contaminação por bactérias acéticas; a segunda é a aeração do mosto durante a fermentação, que estimula a produção de ácido acético pelas leveduras a partir do açúcar metabolizado (Alcarde, 2017).

O ácido acético possui grande influência sobre os sabores e aromas da bebida, sendo responsável por irritação durante a ingestão e odor penetrante e irritante, comumente descrito como odor de vinagre (Lee et al., 2001). A maior concentração de ácido acético foi observada para a aguardente monodestilada, próxima de $42 \mathrm{mg} / 100 \mathrm{~mL}$ a.a. (Tabela 2). A aguardente bidestilada apresentou concentração de ácido acético equivalente a $25 \%$ do teor observado na monodestilada. As aguardentes redestiladas apresentaram as menores médias, representando aproximadamente $15 \%$ da concentração observada na aguardente monodestilada. $\mathrm{O}$ excesso de acidez de uma bebida destilada caracteriza um grave defeito sensorial.

Os aldeídos são de grande importância na composição das aguardentes, sendo, os principais, acetaldeído, furfural e hidroximetilfurfural, os quais apresentam odores penetrantes, geralmente enjoativos. São associados ao mal-estar causado pelo consumo de bebidas alcoólicas em excesso, a chamada "ressaca", tendo sintomas, como náuseas, vômitos, agitação, transpiração, confusão e dores de cabeça. Assim, baixos teores de aldeídos são esperados em uma aguardente de boa qualidade. O acetaldeído, quando em baixa concentração, pode remeter a aromas de frutas, porém, em alta concentração, possui odor pungente. Cortes adequados da fração "cabeça" auxiliam na redução desses compostos nas aguardentes produzidas em alambiques (Nikfardjam \& Maier, 2011). A prática da queima da palha da cana para facilitar a colheita forma o furfural e o hidroximetilfurfural, que também podem se formar pela pirogenação de açúcares residuais da fermentação durante a destilação do vinho. Aldeídos podem também ser formados pela oxidação de álcoois superiores (Parazzi et al., 2008).

Independentemente do teor alcoólico inicial dos flegmas utilizados nas redestilações (30, 40 e 48\% v/v), os destilados alcoólicos redestilados apresentaram composições químicas semelhantes entre si (Tabela 2). Os destilados alcoólicos obtidos a partir de flegmas a $40 \%$ e $48 \%(\mathrm{v} / \mathrm{v})$ apresentaram teores alcoólicos superiores ao do destilado alcoólico obtido a partir do flegma a 30\% (v/v). Apesar da diferença observada para os teores alcoólicos nos redestilados a partir de flegmas com concentrações iniciais de etanol diferentes, foi verificado que a composição química, expressa em miligramas por $100 \mathrm{~mL}$ de álcool anidro, não diferiu entre os tratamentos, o que indica que a qualidade química de aguardentes redestiladas independe da diluição 
do flegma, de forma que a escolha da matriz hidroalcoólica dependerá mais de questões de otimização operacional, de produto e financeira, tais como: disponibilidade do flegma, qualidade e aspectos sensoriais, custo de produção atrelado ao gasto energético e conformidade com a legislação sobre o limite do teor alcoólico do destilado. A redestilação de um flegma com teor de álcool etílico equivalente a $48 \%(\mathrm{v} / \mathrm{v})$, segundo a metodologia abordada, obteve um destilado alcoólico simples muito próximo ao limite estabelecido pela IN13 em relação ao teor de etanol: $69,8 \% \mathrm{v} / \mathrm{v}$ a $20{ }^{\circ} \mathrm{C}$ (Tabela 2).

Os destilados alcoólicos das aguardentes redestiladas apresentaram as menores concentrações de cobre (aproximadamente $0,4 \mathrm{mg} / \mathrm{L}$ ), inferiores à concentração de cobre do destilado alcoólico da aguardente bidestilada $(0,6 \mathrm{mg} / \mathrm{L})$. A aguardente monodestilada apresentou concentração de cobre de $1,98 \mathrm{mg} / \mathrm{L}$, valor abaixo do limite máximo permitido pela legislação brasileira $(5,0 \mathrm{mg} / \mathrm{L})$, porém bem próximo ao limite máximo exigido para exportação $(2,0 \mathrm{mg} / \mathrm{L})$. As aguardentes de cana podem apresentar um defeito sensorial quando destiladas em alambique de aço inoxidável. Este defeito, atribuído à ausência de cobre no destilador, está relacionado à presença de compostos sulfurados na bebida. Esses compostos, particularmente o dimetilsulfeto (DMS), geralmente são responsáveis por aroma desagradável (odor de sulfetos) em aguardentes. $\mathrm{O} \mathrm{Cu}{ }^{2}$ age de forma a catalisar a conversão de sulfetos a sulfatos, reduzindo, portanto, o odor desagradável típico dos sulfetos (Alcarde, 2017).

Em destilações realizadas em alambique simples, Alcarde et al. (2009) constataram redução nas concentrações de cobre, de acidez volátil, de aldeídos, de ésteres, de metanol, de álcoois superiores e dos congêneres totais em aguardentes duplamente destiladas. Trabalhando com alambique retificador, Alcarde et al. (2011) constataram a melhoria da qualidade química de aguardente pelo processo de dupla destilação.

No presente trabalho, a bidestilação, bem como as redestilações, proporcionou redução significativa (> 90\%) na concentração de carbamato de etila dos destilados. Trabalhos da literatura indicam que a metodologia da dupla destilação pode reduzir a concentração de carbamato de etila de destilados. Riffkin et al. (1989) observaram que apenas $1 \%$ da concentração de carbamato de etila formado na primeira destilação foi detectada no whisky produzido pela segunda destilação. A fração "cauda" acumulou $15 \%$ do carbamato de etila e a vinhaça reteve $84 \%$ do carbamato de etila presente na segunda destilação. Nagato et al. (2000) encontraram uma concentração média de $317 \mu \mathrm{g} / \mathrm{L}$ de carbamato de etila em 13 amostras de aguardentes comerciais, no entanto observaram que as amostras com as menores concentrações de carbamato de etila (38 a $48 \mu \mathrm{g} / \mathrm{L})$ eram aguardentes duplamente destiladas. Galinaro \& Franco (2011) observaram que a redestilação proporcionou redução de até 92,5\% da concentração de carbamato de etila de 15 amostras de aguardentes comerciais.

O carbamato de etila é um composto potencialmente carcinogênico que normalmente está presente em bebidas destiladas. Diversos países adotam legislação específica para controlar a presença deste contaminante em bebidas alcoólicas. Precursores da formação de carbamato de etila são ureia e cianeto. A ureia, que pode estar presente no caldo de cana ou ter sido indevidamente adicionada ao mosto, reage com o etanol formando o carbamato de etila. $\mathrm{O}$ íon cianeto é formado pela degradação enzimática de glicosídeos cianogênicos presentes na cana-de-açúcar. O cianeto pode ser oxidado a cianato, o qual, reagindo com o etanol na presença do íon cobre, forma o carbamato de etila. Esta é tida como a principal via de formação de carbamato de etila em aguardentes (Aresta et al., 2001).

No entanto, é importante também salientar que bactérias láticas, contaminantes microbiológicos frequentes no processo de produção de aguardente de cana, metabolizam o aminoácido arginina, formando citrulina, composto precursor da formação de carbamato de etila na bebida (Bortoletto et al., 2015).

Alcarde et al. (2012a), estudando o efeito da dupla destilação na redução da concentração de carbamato de etila em aguardente de cana, observaram que apenas 3\% do carbamato de etila total acumulou-se na aguardente bidestilada. Os autores observaram que, na segunda destilação, as concentrações de cobre e de carbamato de etila aumentaram com o decorrer do processo; no entanto, em função do ponto de corte entre 
as frações "coração" e "cauda" (60\% de etanol v/v), a dupla destilação promoveu redução de 97\% da concentração de carbamato de etila na aguardente. Em outro estudo, Alcarde et al. (2012b) relataram reduções deste contaminante da aguardente de cana variando entre $94 \%$ e $98,5 \%$ dependendo da proporção de refluxo durante a segunda destilação, em diferentes tipos de alambiques.

Franco et al. (2009), visando verificar o efeito do processo de redestilação na qualidade sensorial da aguardente de cana, redestilaram aguardente monodestilada, após diluição a $20 \%, 25 \%$ e $30 \%$ (v/v), e submeteram as aguardentes redestiladas a testes sensoriais de aceitação da bebida em relação a aparência, aroma, sabor, impressão global e atitude de compra. Os resultados obtidos mostraram que o processo de redestilação melhorou a qualidade sensorial da aguardente e que aquela proveniente da redestilação a $30 \%$ de álcool em volume foi a que apresentou as maiores médias em todos os atributos avaliados, sendo significativamente superior para os atributos de sabor e impressão global.

\section{Conclusões}

Em relação à monodestilação, os processos de bidestilação e de redestilação proporcionaram redução da concentração de congêneres voláteis das aguardentes (ácido acético, aldeído acético, acetato de etila, álcool propílico e furfural) e de compostos considerados contaminantes (metanol, sec-butanol, cobre e carbamato de etila). Portanto, como as concentrações dos compostos contaminantes devem ser as menores possíveis e sendo o ácido acético, o aldeído acético e o furfural compostos prejudiciais à qualidade sensorial de aguardentes, os processos de bidestilação e de redestilação produziram aguardentes de melhor qualidade química que o processo de monodestilação.

O teor alcoólico da flegma $(30 \%, 40 \%$ ou $48 \%$ de etanol v/v) não influenciou a composição química dos destilados alcoólicos simples destinados à elaboração da aguardente de cana redestilada.

\section{Agradecimentos}

O presente trabalho foi realizado com apoio da Coordenação de Aperfeiçoamento de Pessoal de Nível Superior - Brasil (CAPES) - Código de Financiamento 001.

\section{Referências}

Alcarde, A. R. (2017). Cachaça: ciência, tecnologia e arte (2. ed., 96 p.). São Paulo: Edgard Blücher.

Alcarde, A. R., Souza, P. A., Bosqueiro, A. C., \& Belluco, A. E. S. (2009). Chemical profile of sugar cane spirit produced by double distillation methodologies in simple still. Alimentos e Nutrição, 20(3), 499-506.

Alcarde, A. R., Souza, P. A., \& Belluco, A. E. S. (2011). Aspectos da composição química de aguardente de cana-de-açúcar produzida por metodologias de dupla destilação em alambique retificador. Ciência e Tecnologia de Alimentos, Campinas, 31(2), 355-360. http://dx.doi.org/10.1590/S0101-20612011000200012

Alcarde, A. R.; Souza, L. M.; Bortoletto, A. M. (2012a). Ethyl carbamate kinetics in double distillation of sugar cane spirit. Journal of the Institute of Brewing, 118(1), 27-31.

Alcarde, A. R., Souza, L. M., \& Bortoletto, A. M. (2012b). Ethyl carbamate kinetics in double distillation of sugar cane spirit: Part 2 Influence of type of pot still. Journal of the Institute of Brewing, 118(4), 352-355. http://dx.doi.org/10.1002/jib.48

Amerine, M. A., \& Ough, C. S. (1976). Análisis de Vinos y Mostos (160 p.). Zaragoza: Acribia.

Aresta, M., Boscolo, M., \& Franco, D. W. (2001). Copper (II) catalysis in cyanide conversion into ethyl carbamate in spirits and relevant reactions. Journal of Agricultural and Food Chemistry, 49(6), 2819-2824. PMid:11409971. http://dx.doi.org/10.1021/jf001346w

Bortoletto, A. M., \& Alcarde, A. R. (2013). Congeners in sugar cane spirits aged in casks of different woods. Food Chemistry, 139(1-4), 695-701.

Bortoletto, A. M., Silvello, G. C., \& Alcarde, A. R. (2015). Chemical and microbiological quality of sugar cane juice influences the concentration of ethyl carbamate and volatile congeners in cachaça. Journal of the Institute of Brewing, 121(2), 251-256. http://dx.doi.org/10.1002/jib.213

Brasil. Ministério da Agricultura, Pecuária e Abastecimento. (2005a, junho 30). Aprova o Regulamento Técnico para Fixação dos Padrões de Identidade e Qualidade para Aguardente de Cana e para Cachaça (Instrução Normativa n ${ }^{13}$, de 29 de junho de 2005). Diário Oficial da União, Brasília, seção 1. 
Brasil. Ministério da Agricultura, Pecuária e Abastecimento. (2005b, setembro 9). Aprova o Manual Operacional de Bebidas e Vinagres. Instrução Normativa n 24, de 8 de setembro de 2005. Diário Oficial da União, Brasília, seção 1.

Franco, A. C., Rota, M. B., \& Faria, J. B. (2009). The redistillation and your influence in sensory quality. Alimentos e Nutrição, 20(2), 331-334.

Galinaro, C. A., \& Franco, D. W. (2011). Formação de carbamato de etila em aguardentes recém-destiladas: proposta para seu controle. Química Nova, 34(6), 996-1000.

Kruger, L. (1998). Yeast metabolismo and its effect on flavour: part 2. Brewers Guardian, 127, 27-30.

Lanças, F. M. (2009). Cromatografia Líquida (382 p.). Campinas: Átomo.

Lee, Y. M., Paterson, A., Piggot, J. R., \& Richardson, G. D. (2001). Origins of Flavour in Whiskies and a revised flavour wheel: a review. Journal of the Institute of Brewing, 107(5), 287-313. http://dx.doi.org/10.1002/j.2050-0416.2001.tb00099.x

Moreira, R. F. A., Neto, C. C., \& Maria, C. A. B. (2012). A fração volátil das aguardentes de cana produzidas no Brasil. Química Nova, 35(9), 1819-1826.

Mota, D., Luis, A., Cerveira, O., Anjos, O., Canas, S., \& Caldeira, I. (2010). Teores de metanol em aguardentes vínicas e bagaceiras portuguesas. $8^{\circ}$ Simpósio de Vitivinicultura do Alentejo (pp. 437-445). Évora: Ateva.

Murray, D. (2014). Grain whisky distillation. In I. Russel \& G. Stewart (Eds.), Whisky technology, production and marketing (2. ed., Chapter 10, pp. 179-198). Oxford: Academic Press.

Nagato, L. A. F., Silva, O. A., Yonamine, M., \& Penteado, M. V. C. (2000). Quantitation of ethyl carbamate (EC) by gas chromatography and mass spectrometric detection in distilled spirits. Alimentaria, 37(311), 31-36.

Nikfardjam, M. P., \& Maier, D. (2011). Development of a headspace trap HRGC/MS method for the assessment of the relevance of certain aroma compounds on the sensorial characteristics of commercial apple juice. Food Chemistry, 126, 1926-1933.

Nóbrega, I. C. C. (2003). Análise dos compostos voláteis da aguardente de cana por concentração dinâmica do "headspace" e cromatografia gasosa-espectrometria de massas. Ciência e Tecnologia de Alimentos, 23(2), 210-216.

Paine, A., \& Davan, A. D. (2001). Defining a tolerable concentration of methanol in alcoholic drinks. Human \& Experimental Toxicology, 20(11), 563-568.

Parazzi, C., Arthur, C. M., Lopes, J. J. C., \& Borges, M. T. M. R. (2008). Avaliação e caracterização dos principais compostos químicos da aguardente de cana-de- açúcar envelhecida em tonéis de carvalho (Quercus sp.). Ciência e Tecnologia de Alimentos, 28(1), 193-199.

Pimentel-Gomes, F., \& Garcia, C. H. (2002). Estatística aplicada a experimentos agronômicos e florestais: exposição com exemplos e orientações para uso de aplicativos (309 p.). Piracicaba: FEALQ.

Piva, J. P.; Garcia, P. C. R.; Martha, V. F. (1999). Distúrbios do equilíbrio ácido-básico. Jornal de Pediatria, 75(2), $234-243$.

Quain, D. E., \& Duffield, M. L. (1985). A metabolic function for higher alcohol production by yeast. 21ST Congress of the European Brewery Convention (pp. 417-424). Madrid: EBC.

Riffkin, H. L., Wilson, R., Howie, D., \& Muller, S. B. (1989). Ethyl carbamate formation in the production of pot still whisky. Journal of the Institute of Brewing, 95(2), 115-119. http://dx.doi.org/10.1002/j.2050-0416.1989.tb04618.x

Vilela, F. J., Cardoso, M. G., Masson, J., \& dos Anjos, J. P. (2007). Determinação das composições físico-químicas de cachaças do sul de minas gerais e de suas misturas. Ciência e Agrotecnologia, 31(4), 1089-1094.

Whitby, B. R. (1992). Traditional distillation in the whisky industry. Ferment, 5(4), 261-266.

Wilson, N. R. (2008). The effect of lactic acid bacteria on congener composition and sensory characteristics of Scotch malt whisky (Thesis Ph.D.). Heriot-Watt University, Edimburgo. 